\title{
Morphological re-examination reveals that Campylomyza serrata JASCHHOF, 1998 is a complex of five cryptic species (Diptera: Cecidomyiidae, Micromyinae)
}

\author{
With 13 figures \\ MATHIAS JASCHHOF ${ }^{1}$ \\ ${ }^{1}$ Station Linné, Ölands Skogsby 161, SE-38693 Färjestaden, Sweden. - mjaschhof@yahoo.de \\ Published on 2015-12-21
}

\section{Zusammenfassung}

Die zur Unterfamilie Micromyinae gehörende Gallmücke Campylomyza serrata wurde vom Autor im Jahre 1998 nach drei Männchen von einem norddeutschen Fundort beschrieben. Seitdem wurden zahlreiche nachträglich gesammelte Exemplare aus mehreren europäischen Ländern dieser Art zugeordnet und als C. serrata publiziert. Nun, fast 20 Jahre später, wurden alle diese Exemplare und einige andere aus bislang undeterminiertem Campylomyza-Material in der Sammlung des Autors - insgesamt 56 Männchen - zusammengezogen und morphologisch nachuntersucht. Im Ergebnis dieser Untersuchung wurde offenbar, dass Campylomyza serrata sensu JAschHof (1998) ein Komplex aus fünf Kryptospezies ist, einschließlich Campylomyza angulata spec. nov., Campylomyza appendiculata spec. nov., Campylomyza lapponica spec. nov. und Campylomyza zwii spec. nov. In der vorliegenden Arbeit werden Campylomyza serrata und die ihr nahe verwandten Arten aufgrund von Genitalmerkmalen der Männchen definiert. Ein Schlüssel zur Bestimmung der Männchen wird vorgelegt, der die genannten Arten und Campylomyza spinata, den sechsten Vertreter der serrata-Gruppe, einbezieht. Schließlich werden Bestimmungsprobleme diskutiert, wie sie bei der praktischen Arbeit an der serrata-Gruppe (und anderen schwer bestimmbaren Micromyinen) auftreten.

\section{Key words}

Palearctic region, gall midges, species identification, morphology, DNA barcoding

\section{Summary}

The micromyine gall midge Campylomyza serrata was described by the author in 1998 on the basis of three male specimens from a single locality in Northern Germany. Since then, a number of additional specimens from several European countries were assigned to this species and published as C. serrata. Now, almost 20 years later, all these specimens plus a few others from previously undetermined Campylomyza material in the author's collection, altogether 56 males, were gathered for a morphological re-examination. As a result, Campylomyza serrata sensu JAsCHHOF (1998) is revealed to be a complex of five cryptic species, including Campylomyza angulata spec. nov., Campylomyza appendiculata spec. nov., Campylomyza lapponica spec. nov., and Campylomyza zwii spec. nov. In the present paper, Campylomyza serrata and the new species related to it are defined using characters of the male genitalia. A key is provided that facilitates the identification of males of these species and of Campylomyza spinata, the sixth known member of the serrata group. Finally, various issues related to the identification of serrata-like species (and other taxonomically difficult Micromyinae) are discussed. 


\section{New taxa}

Campylomyza angulata spec. nov., Campylomyza appendiculata spec. nov., Campylomyza lapponica spec. nov., Campylomyza zwii spec. nov.

\section{Introduction}

The genus Campylomyza MeIGen provides a prime example of the difficulties involved in the morphological identification of gall midges of the subfamily Micromyinae. With 34 extant, mostly Palearctic species named, this genus is medium-sized, but one may expect that there are many undescribed species, several of which are known to the author and many more not yet collected. At present, male genitalia provide the only morphological characters diagnostic of species. Structures of taxonomic relevance are the gonocoxites, gonostyli and parameres, the latter joined to form a tegmen. All these parts are distinguished by a complex three-dimensional structuring. This complexity, on the one hand, provides us with a number of potentially useful characters; on the other hand, character states are difficult to understand from the essentially two-dimensional picture seen with a transmitted-light microscope, which is the standard method used in the routine identification of Micromyinae species. There is also the fact that even the slightest distortions of such tiny structures may cause dramatic changes in appearance-something known to careful students of these midges as preparation artifacts (cf. JaschHOF \& JAschHof 2009: 31f.). Like most other Micromyinae, Campylomyza are very small, with body length of usually less than $2 \mathrm{~mm}$.

The Holarctic species of Campylomyza have twice been the subject of taxonomic revision in recent years (JaschHof 1998b, JaschHof \& JaschHof 2009). An improvement to the 2009 revision is that two elusive taxa, Campylomyza flavipes Meigen, 1818 and Campylomyza ormerodi (KIEFFER, 1913), could be shown to be species complexes. Careful study of new material at that time revealed the flavipes group to contain 9, and the ormerodi group to contain 6 distinct species (JASCHHOF \& JASCHHOF 2009). The serrata group, which is the subject of the present paper, was established by JAschHoF \& JAschноғ (2009) for 2 species: the widespread European Campylomyza serrata JaschHoF, 1998 and the Far East Russian Campylomyza spinata JaschHof, 1998.

Here I demonstrate that Campylomyza serrata sensu JASCHHOF (1998a) is actually a group of five cryptic species. This insight is not so much the result of studying new specimens but rather of studying previously known specimens again, this time in a body. Acquired experience in assessing slight morphological differences also plays a role here. The newly recognized species-Campylomyza angulata spec. nov., Campylomyza appendiculata spec. nov., Campylomyza lapponica spec. nov., and Campylomyza zwii spec. nov-are described and Campylomyza serrata is redefined. A key to the species of the serrata group is presented, based on characters of the male genitalia, so as to facilitate the morphological identification of hidden biodiversity in this difficult group. Specimens in my collection indicate the presence of another one or two serrata-like species in Europe, but this material is insufficient for description. The serrata group has, to present knowledge, an exclusively Palearctic distribution, but I would not be surprised to learn of its presence in North America where Campylomyza has been poorly studied. Finally, I take this opportunity to reflect about evolutionnot of Campylomyza or Micromyinae but of the skills of a morphotaxonomist.

\section{Material and Methods}

Specimens of Campylomyza serrata sensu JAsCHHOF (1998a) studied here came from the Naturhistoriska Riksmuseet Stockholm (NHRS), the Senckenberg Deutsches Entomologisches Institut Müncheberg (SDEI), and undetermined material in the author's collection at Station Linné, Öland, Sweden. Specimens are returned to their holding institutions, and those that were previously unidentified are shared between NHRS and SDEI. The material, available as microscope slide preparations, was studied by transmitted-light microscope at 400-times or lower magnification. The routine of preparing and studying specimens of Micromyinae has repeatedly been described, most recently by JasCHHOF and JASCHHOF (2009). In the illustrations given here, arrows indicate the most relevant diagnostic characters. Morphological terms that are not commonly used are explained in Figures 5-7. Identifications and distribution data given here make those published earlier for C. serrata (JAsCHHOF 1998b, 2009; JASCHHOF \& JASCHHOF 2009; JAsCHHOF et al. 2014) obsolete.

\section{Taxonomy}

\section{Campylomyza serrata group}

Species of the serrata group are characterized by the tegmen that has a pair of finely serrate processes (JaschHof \& JaschHof 2009). The serration is not obvious in all the specimens studied and is perhaps variable within a species. According to the orientation of these processes and to the size of the aedeagal head, two subgroups can be distinguished. In Campylomyza spinata and $C$. $z w i$, which make up one of the subgroups, the 
processes are turned posteriorly, so as to form the apex of the tegmen $(\leftarrow$, Fig. 13), and the aedeagal head is large $(\leftarrow$, Fig. 13). In the other subgroup, which contains $C$. angulata, C. appendiculata, C. lapponica, and C. serrata, the tegminal processes are situated subapically dorsomedially in a longitudinal direction $(\leftarrow$, Fig. 11), and the aedeagal head is small- $(\leftarrow$, Fig. 10$)$ to medium-sized $(\leftarrow$, Fig. 7). Another peculiarity of the serrata group is that the medial gonocoxal bridges, which in Campylomyza are usually unmodified, have the tendency to project dorsomedially, either in their entirety $(\leftarrow$, Fig. 6$)$ or by sending out narrow processes (JASCHHOF 1998b: Fig. 58a).

\section{Campylomyza angulata spec. nov.}

(Figs 1-4)

Diagnostic description: Campylomyza angulata and C. appendiculata (described below) are the only species of the serrata group whose gonostyli have a distinct convexity or lobe dorsally. The lobe is most obvious in lateral view, but emerges also in a dorsal aspect, in which the edge of the lobe appears as a thick, dark line $(\leftarrow$, Fig. 1$)$. The lobe in C. angulata ( $\leftarrow$, Fig. 1 ) is smaller than that in C. appendiculata ( $\leftarrow$, Fig. 5). The tegmina of the two species are clearly different. In C. angulata, the tegmen is broadened towards the apex; it has no distinct shoulders $(\leftarrow)$; its apical margin is more or less clearly angulate $(\leftarrow)$; and the parameral apodemes are of moderate size (Figs 2, 4). In C. appendiculata, the medial portion of the tegmen is parallel-sided; small shoulders are present; the apical margin is straight (except for the two points medially that are present in all the species treated here); and the parameral apodemes are longer than in any other species of the serrata group ( $\leftarrow$, Fig. 7 ). Other diagnostic characters of $C$. angulata are as follows. The ninth tergite is moderately wide to narrow (Fig. 3). The ventral emargination of the gonocoxites is deep (i.e. the ventral bridge is short) and reinforced by a bare sclerotized rim basally; the medial bridges are not or only slightly bulged posteriorly and only slightly project dorsomedially; the dorsal bridge reaches far anteriorly; and there are large membranous areas close to the insertion points of the gonostyli $(\leftarrow$, Fig. 3 ). The gonostylus is broadly rounded apically (Fig. 3). The aedeagal head is medium-sized (Fig. 3).

Etymology: The Latin adjective angulata means angulate, with reference to the shape of the tegmen.

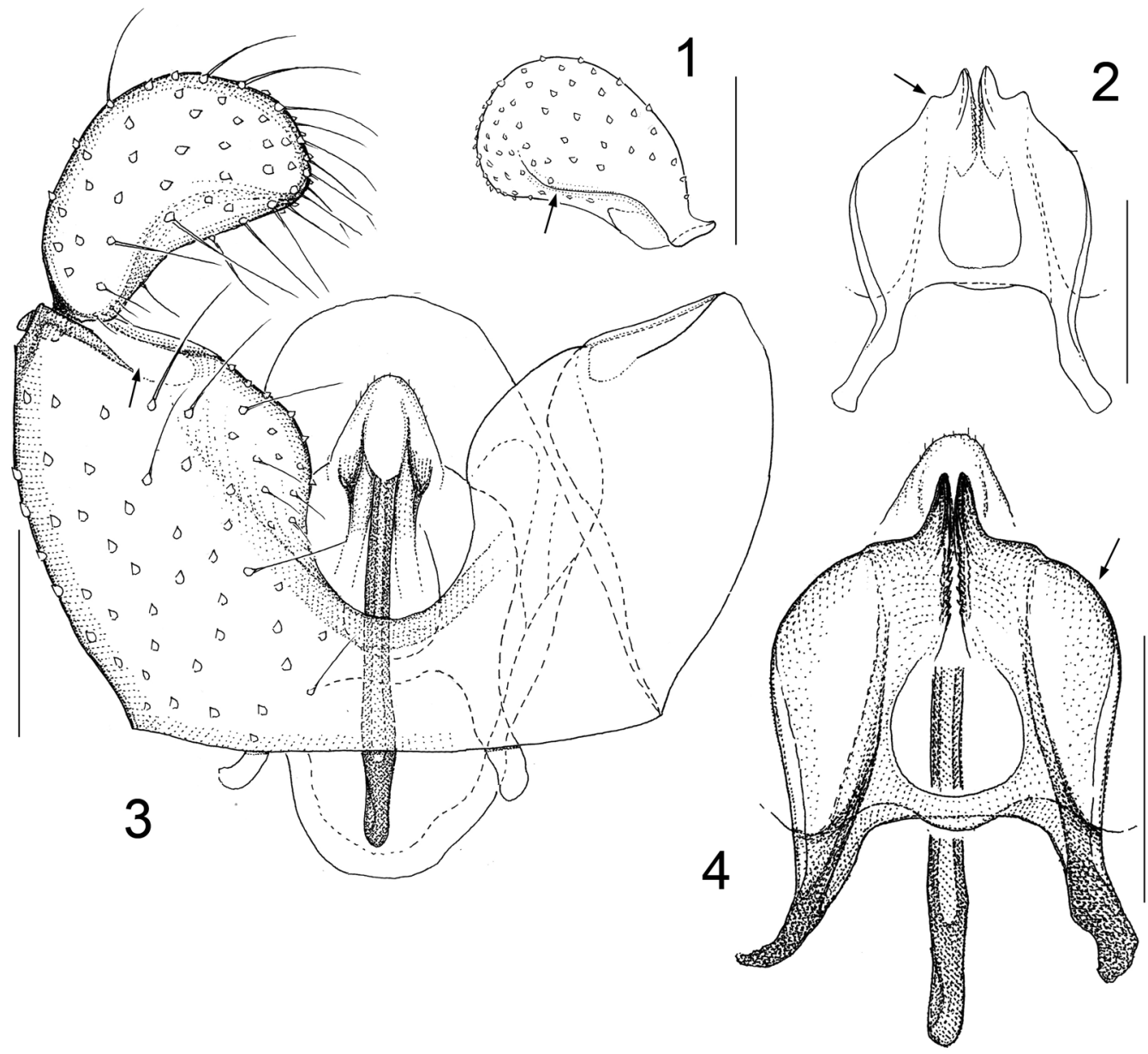

Figs 1-4: Campylomyza angulata spec. nov., male. - 1: gonostylus (paratype), dorsal; - 2: tegmen (paratype), ventral; - 3: genitalia (holotype), ventral; - 4: tegmen, ejaculatory apodeme indicated (holotype), ventral. Scale bar $=0.05 \mathrm{~mm}$. 
Distribution: South to north Sweden (Skåne, Södermanland, Uppland, Västerbotten, Pite Lappmark), south to north Finland (Nylandia, Tavastia australis, Kuusamo), central Japan (Honshu).

Types: Holotype. Male (FENN1640; NHRSGULI000019912), Sweden, Norrbotten, Boden, Krokliden Reserve, 1994-06-13-07-20, Malaise trap over aspen log, B. Viklund (in NHRS). Paratypes. 3 males (FENN1637-1639; NHRS-GULI000019909-19911), same data as the holotype.

Other specimens studied: Sweden: Skåne: male (FENN1648; NHRS-GULI000019914), Klippan, Skäralid, 2004-05-20-06-11, The Swedish Malaise Trap Project (SMTP); Södermanland: 2 males (FENN 1649-1650; NHRS-GULI000019915-19916), Tyresta, 1999-05-05-0528 and 2001-05-10-05-26, B. Viklund, L.O. \& H. Ahnlund; male (A4522), same locality, 1999-05-05-05-28, B. Viklund; Uppland: 2 males (A4518-4519), Lövsta- bruk, 1994-06-08, H. Hippa \& B. Gustafsson; 2 males (FENN1649-1650; NHRS-GULI000019917, 19922), Knivsta, Rickebasta, 2004-07-11-08-07, SMTP; Västerbotten: 5 males (FENN1632-1636; NHRSGULI000019904-19908), 5 km SE Lövånger, Kallviken, 1997-06-25-09-15, H. Sporrong \& B. Viklund; Pite Lappmark: male (A4522), Kåbdalis, Suorke State Reserve 40 km NE Moskosel, 1993-05-31-09-23, B. Viklund. Finland: Nylandia: male (FENN2763; NHRS-GULI000019928), Sipoo, Hindsby, 2004-07-14-07-22, P. Vilkamaa; Tavastia australis: male (FENN1630; NHRS-GULI000019902), Lammi, Evo, Lapinjärvi, 2004-07-27-08-12, J. Jakovlev; Kuusamo: male (FENN1631; NHRS-GULI000019903), Kuohusuo-Kalliovaara 30 km S Kuusamo, 2004-07-31-0802, M. Jaschhof. Japan: Honshu: 2 males (A7609-7610), Yamanashi Prefecture, Oyama Town, east slope of Mt. Fuji, 1999-06-04-06-13, M. \& C. Jaschhof.

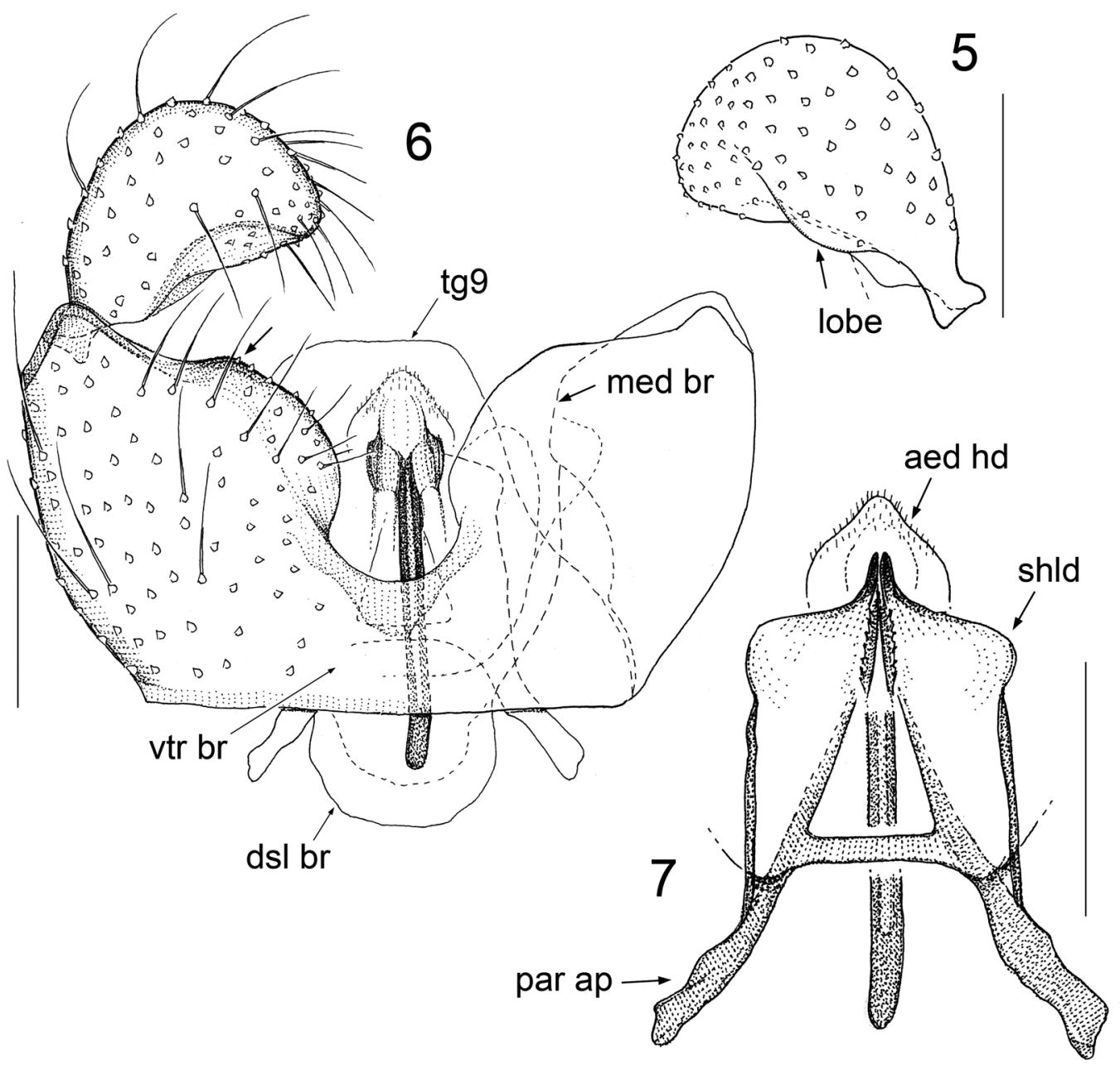

Figs 5-7: Campylomyza appendiculata spec. nov., male holotype. - 5: gonostylus, dorsal; - 6: genitalia, ventral; - 7: tegmen, ejaculatory apodeme indicated, ventral. Scale bar $=0.05 \mathrm{~mm}$. Abbreviations: aed hd $=$ aedeagal head, dsl br $=$ dorsal gonocoxal bridge, med br = medial gonocoxal bridge, par ap = parameral apodeme, shld = shoulder of tegmen, $\operatorname{tg} 9=$ ninth tergite, vtr br $=$ ventral gonocoxal bridge. 


\section{Campylomyza appendiculata spec. nov.}

(Figs 5-7)

Diagnostic description: Campylomyza appendiculata is unmistakably identified by the following combination of characters: the gonostyli have a large dorsal lobe ( $\leftarrow$, Fig. 5 ); the largely parallel-sided tegmen has small shoulders $(\leftarrow)$ and conspicuously long parameral apodemes $(\leftarrow$, Fig. 7$)$; the aedeagal head is more densely covered with microtrichia than in the other species of the serrata group ( $\leftarrow$, Fig. 7 ); and the medial bridges of the gonocoxites project posteriorly ( $\leftarrow$, Fig. 6$)$. Other diagnostic characters of $C$. appendiculata are as follows. The ninth tergite is moderately wide to narrow (Fig. 6). The ventral emargination of the gonocoxites is moderately deep (i.e. the ventral bridge is rather long) and reinforced by a broad, bare sclerotized rim basally; the medial bridges strongly project dorsomedially $(\leftarrow)$; and the dorsal bridge, which is narrow, reaches far anteriorly (Fig. 6). The gonostylus is strongly convex posteriorly, narrowly rounded apically, and strongly excavated ventromedially (Fig. 6). The aedeagal head is mediumsized (Fig. 6).
Etymology: The Latin adjective appendiculata means elongated, with reference to the unusually long parameral apodemes.

Distribution: South Norway (inner Hordaland), south to central Finland (Regio aboensis, Satakunta, Savonia australis, Karelia borealis), Netherlands (NoordBrabant), north to central Japan (Hokkaido, Honshu).

Types: Holotype. Male (FENN2764; NHRSGULI000019929), Finland, Karelia borealis, Outokumpu, Lake Sysmajärvi, in birch / alder forest, 2004-06-18, sweepnet, M. Jaschhof (in NHRS). Paratypes. Male (FENN1626; NHRS-GULI000019898), Finland, Regio aboensis, Vihti, Salmi, 2004-05-27, M. Jaschhof; male (FENN1627; NHRS-GULI000019899), Finland, Satakunta, Ikaalinen, Seitseminen National Park, Kuru, N Pitkajärvi, 2004-0605-06-29, M. \& C. Jaschhof; 2 males (FENN1628-1629; NHRS-GULI000019900-19901), Finland, Savonia australis, Kerimäki, Sulkavanniemi, 2004-06-19, M. Jaschhof.

Other specimens studied: Norway: 2 males (FENN16521653; NHRS-GULI000019924-19925), Eidfjord, Simadalen, Tveit, 2003-09-06-10-18, E. Rindal. Netherlands: Noord-Brabant: 2 males (A4517, 4521), NE

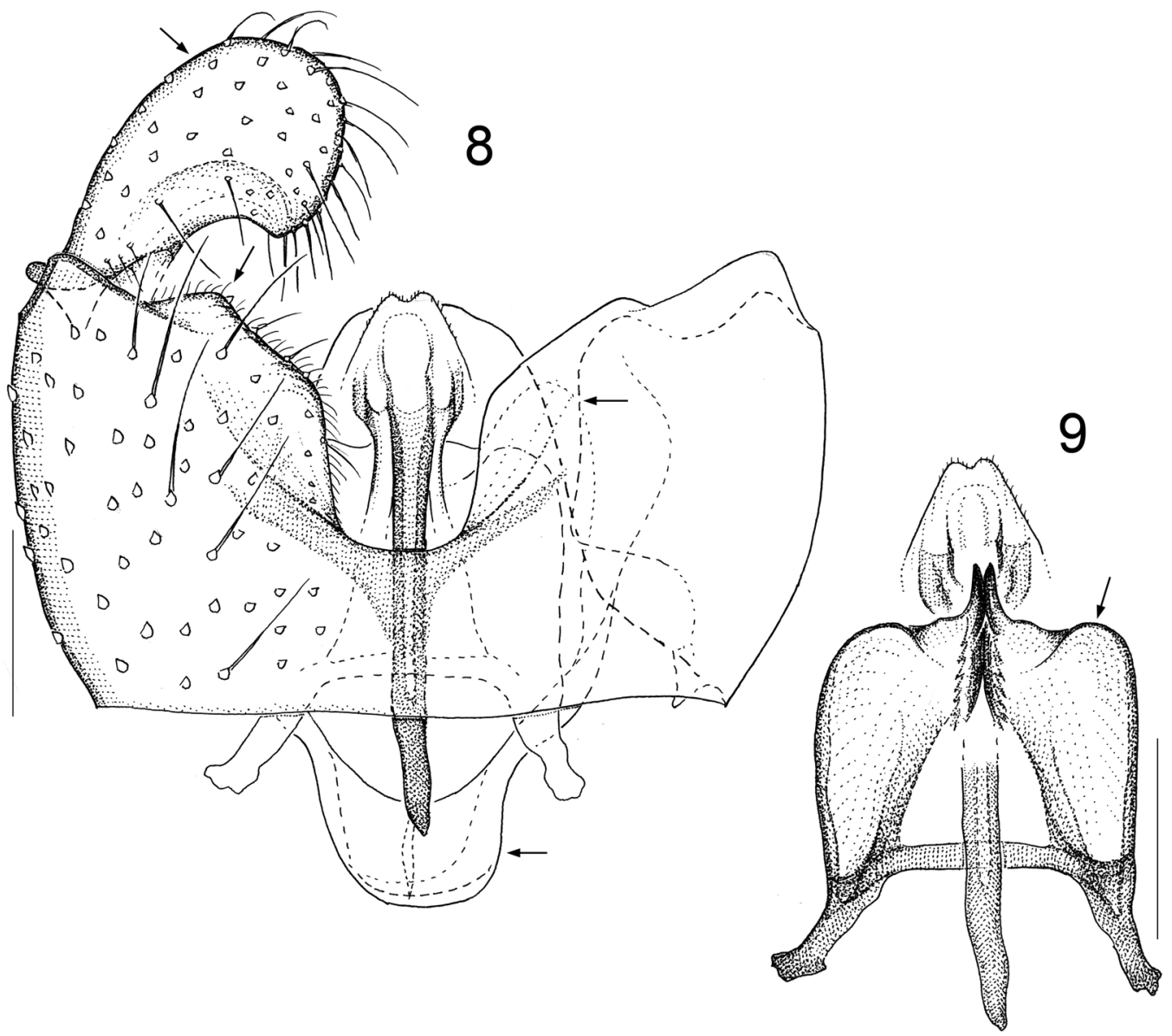

Figs 8-9: Campylomyza lapponica spec. nov., male holotype. - 8: genitalia, ventral; - 9: tegmen, ejaculatory apodeme indicated, ventral. Scale bar $=0.05 \mathrm{~mm}$. 
Tilburg, De Brand Nature Reserve near Udenhout, 199004-28-05-06 and 1990-07-08, van Zuijlen (both mounted on same slide together with C. serrata). Japan: Hokkaido: 2 males (A7611-7612), Tomakomai City, University of Hokkaido Experimental Forest, 1999-05-19, Tomakomai Experimental Forest Research Station; Honshu: 2 males (A7613-7614), Ibaraki Prefecture, Abukuma Highlands, Kitaibaraki City, Sadanami, Ogawa Research Forest, 1996-05-14-05-27, K. Maeto.

\section{Campylomyza lapponica spec. nov.} (Figs 8-9)

Diagnostic description: Many of the diagnostic characters used in the serrata group are especially pronounced in Campylomyza lapponica. The medial gonocoxal bridges, which strongly project both posteriorly $(\leftarrow)$ and dorsomedially $(\leftarrow)$, have conspicuously large microtrichia (Fig. 8); the dorsal gonocoxal bridge is very narrow and strongly projects anteriorly $(\leftarrow$, Fig. 8); the gonostyli are strongly convex posteriorly $(\leftarrow)$ and strongly excavated ventromedially (Fig. 8); the tegminal shoulders are distinct $(\leftarrow)$ and the tegminal processes are of considerable length (Fig. 9). While the gonostyli in the other species of the serrata group are thick, especially in the lobe-bearers, those of $C$. lapponica are laterally compressed-a peculiarity not apparent in Figure 8. Other diagnostic characters of this species are as follows. The ninth tergite is narrow (Fig. 8). The ventral emargination of the gonocoxites is moderately deep (i.e. the ventral bridge is rather long) and reinforced by a broad, bare sclerotized rim basally (Fig. 8). The parameral apodemes are short (Fig. 9). The aedeagal head is medium-sized (Fig. 8).

Etymology: The Latin adjective lapponica refers to the distribution of this species in Lapland (lat. Lapponia).

Distribution: North Sweden (Pite Lappmark, Norrbotten).

Types: Holotype. Male (A4516), Sweden, Pite Lappmark, Arjeplog, Laisvik, Vuordnats, in mixed forest of birch and spruce, 1993-05-23-08-20, Malaise trap, B. Viklund (in SDEI). Paratype. Male (FENN1641; NHRS-GULI000019913), Sweden, Norrbotten, Niemisel, Blåkölen State Forest Reserve, 1994-06-13-07-20, B. Viklund.

\section{Campylomyza serrata JASCHHOF, 1998}

(Fig. 10-11)

Diagnostic description: Campylomyza serrata can be identified by the following characters in combination. The ninth tergite is moderately wide to narrow (Fig. 10). The ventral emargination of the gonocoxites is deep $(\leftarrow$, i.e. the ventral bridge is short) and only weakly reinforced basally; the medial bridges do not project; and the dorsal bridge, which is somewhat wider than in the

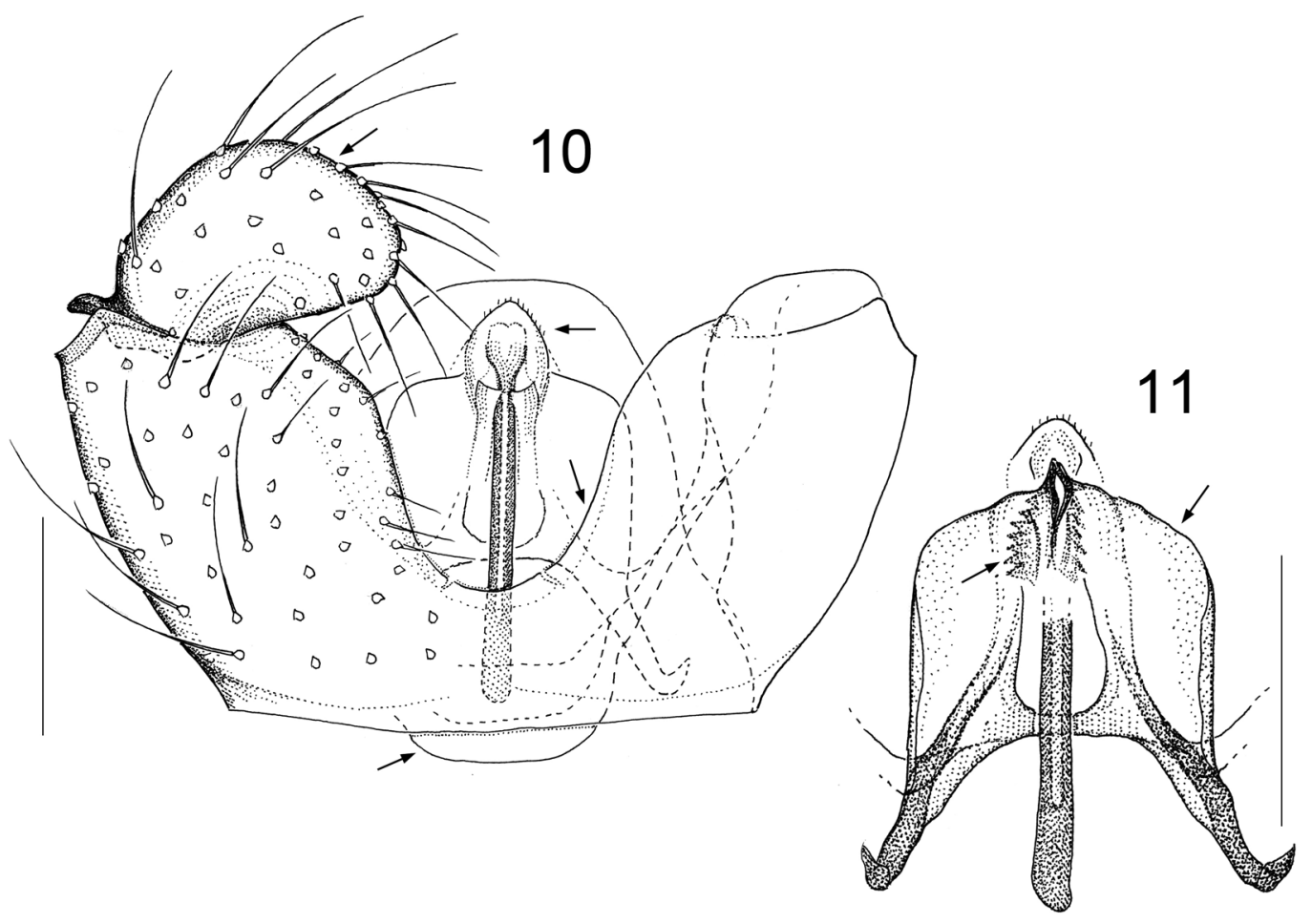

Figs 10-11: Campylomyza serrata JaschноF, 1997; male holotype. - 10: genitalia, ventral; - 11: tegmen, ejaculatory apodeme indicated, ventral. Scale bar $=0.05 \mathrm{~mm}$. 
other species of the serrata group, protrudes only slightly beyond the ventroanterior margin $(\leftarrow$, Fig. 10). The short gonostyli $(\leftarrow)$ are moderately convex posteriorly and broadly rounded apically (Fig. 10). The parallel-sided tegmen has no shoulders $(\leftarrow)$, short serrate processes $(\leftarrow)$, and a slightly angulate apical margin; the transverse arch connecting the parameres is short (Fig. 11). Campylomyza serrata has the smallest aedeagal head $(\leftarrow$, Fig. 10) of all the members of this group.

Remarks: Figure 3c" in JASCHHOF (1998a) and figure 57d in JASCHHOF (1998b), both published under the name of Campylomyza serrata, actually depict the tegminal processes of Campylomyza zwii (described below).

Distribution: South Norway (Akershus, western Buskerud, outer Aust-Agder), central Sweden (Uppland), Netherlands (Noord-Brabant), northeast Germany (Mecklenburg-Vorpommern), central Japan (Honshu).

Specimens studied: Norway: Akershus: 2 males (FENN3347-3348), Ås, Årungen, Syverud, 200307-08-08-15, E. Rindal; western Buskeryd: 2 males (FENN2765-2766; NHRS-GULI000019926-19927), Hol, Geilo, Kikut, 2003-07-04-07-27, E. Rindal; outer Aust-Agder: male (FENN1651; NHRSGULI000019923), Lillesand, Furulia, 2004-08-09,
G. Wiig. Sweden: Uppland: 4 males (FENN1643-1646; NHRS-GULI000019918-19921), Knivsta, Rickebasta, 2004-07-11-08-07, SMTP. Netherlands: Noord-Brabant: 2 males (A4517, 4521), NE Tilburg, De Brand Nature Reserve near Udenhout, 1990-04-28-05-06 and 199007-08, van Zuijlen (both mounted on same slide together with C. appendiculata). Germany: Mecklenburg-Vorpommern: holotype male and 2 paratype males (see JAschноғ 1998a). Japan: Honshu: male (A7615), Ibaraki Prefecture, Abukuma Highlands, Kitaibaraki City, Sadanami, Ogawa Research Forest, 1996-05-14-05-27, K. Maeto.

\section{Campylomyza zwii spec. nov.}

(Figs 12-13)

Diagnostic description: Campylomyza zwii is clearly distinguished from the other species of the serrata group in Europe by two characters: the tegminal processes, which are turned posteriorly, form the apex of the tegmen $(\leftarrow$, Fig. 13), and the blunt-ended aedeagal head is so large that it occupies almost all the ventral gonocoxal emargination ( $\leftarrow$, Figs 12-13). Campylomyza spinata from the Far East of Russia is similar in this respect, but has - unlike all the other serrata-like species - the medial gonocoxal bridges equipped with 2 processes (JASCHHOF 1998a:

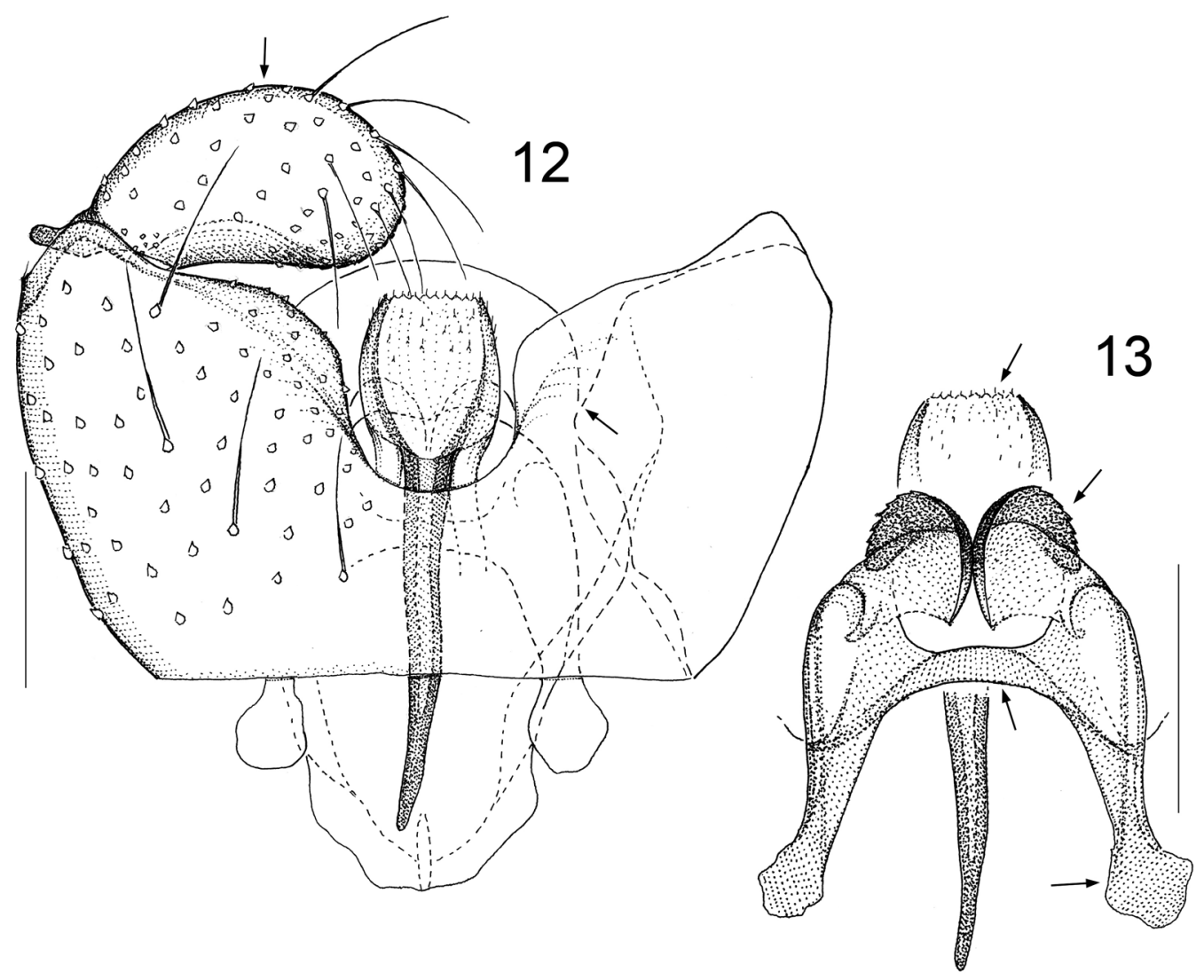

Figs 12-13: Campylomyza zwii spec. nov., male holotype. - 12: genitalia, ventral; - 13: tegmen, ejaculatory apodeme indicated, ventral. Scale bar $=0.05 \mathrm{~mm}$. 


\section{Key to species of the Campylomyza serrata group (males)}

1 Aedeagal head large, blunt-ended (Fig. 12). Tegminal processes turned posteriorly, forming the apex of tegmen (Fig. 13)

Aedeagal head smaller, convex (Fig. 3) or slightly concave (Fig. 8) apically. Tegminal processes situated subapically on the dorsal side of tegmen (Fig. 4)

2 Medial gonocoxal bridges with a pair of narrow processes. Apex of gonostylus narrowly rounded spinata

Medial gonocoxal bridges without processes (Fig. 10). Apex of gonostylus broadly rounded (Fig. 10) $z w i i$

3 Gonostylus with dorsal lobe (Fig. 1)

Gonostylus without dorsal lobe

5

4 Gonostylus lobe small (Fig. 1). Tegmen without shoulders, posterior margin angulate (Figs 2, 4). Parameral apodemes normally long (Fig. 4) angulata

Gonostylus lobe large (Fig. 5). Tegmen with small shoulders, posterior margin straight (Fig. 7). Parameral apodemes conspicuously long (Fig. 7) appendiculata

5 Gonostylus not curved, moderately convex posteriorly (Fig. 10). Dorsal gonocoxal bridge short (Fig. 10). Tegmen without shoulders (Fig. 11) serrata

Gonostylus slightly curved, strongly convex posteriorly (Fig. 8). Dorsal gonocoxal bridge long (Fig. 8). Tegmen with shoulders lapponica

Fig. 4a; 1998b: Fig. 58a). Other diagnostic characters of C. $z$ wii are as follows. The ninth tergite is wide (Fig. 12). The ventral emargination of the gonocoxites is shallow (i.e. the ventral bridge is long) and only weakly reinforced basally; the medial bridges do not project posteriorly but clearly do so dorsomedially $(\leftarrow)$; and the dorsal bridge, which is narrow, reaches far anteriorly (Fig. 12). The elongate gonostylus $(\leftarrow)$ is broadly rounded apically (Fig. 12). The parallel-sided tegmen has no shoulders; the transverse arch connecting the parameres is situated far posteriorly $(\leftarrow)$; and the parameral apodemes are larger than is normal in serrata-like species except C. spinata $(\leftarrow$, Fig. 13).

Etymology: This species is named after Thorsten ("Zwi") Zwinger, Neuenkirchen near Greifswald, for his support of my work on gall midges.

Distribution: Central Sweden (Uppland), east and south Germany (Brandenburg, Sachsen-Anhalt, Thüringen, Bayern), Austria (Salzburg), east Czech Republic (Moravia).

Types: Holotype. Male (A7616), Germany, Brandenburg, Schorfheide-Chorin Biosphere Reserve, Barnim, Klein Ziethen, Kernberge at Serwester See, 2004-07-21, Malaise trap, SDEI (in SDEI). Paratypes. 4 males (A7617-7620), same locality as holotype, 2004-05-19, 2004-07-08, 201407-14, 2005-06-29.

Other specimens studied: Sweden: Uppland: male (A4520), Lövstabruk, 1992-09-10, H. Hippa \& B. Gustafsson. Germany: Sachsen-Anhalt: male (A4510), Harz, Benneckenstein, 1989-06-01, F. Menzel; Thürin- gen: male (A4511), Thüringer Wald, Luisenthal $5 \mathrm{~km} \mathrm{~S}$ Ohrdruf, Käfernburg, 1989-05-27, F. Menzel; Bayern: 2 males (A7621-7622), Oberpfalz, Neumarkt, MainDonau-Kanal, Rappersdorf, 1988-05-15-05-30, Warncke Project. Austria: Salzburg: male (A4515), Ferleiten, 199307-13, F. Menzel. Czech Republic: Moravia: male (A7623), Bile Karpaty, Klabenka, 2008-06-03, J. Ježek.

\section{Discussion}

Taxonomic study of Campylomyza and Micromyinae over the past 200 years has focused, with only a few exceptions, on the morphology of adults (cf. JASCHHOF \& JASCHHOF 2009: 18ff.). Since Frederick W. Edwards' studies in the 1930s the insight has solidified that male morphology, in particular genital characters, are most relevant for distinguishing among closely related species. The present study corroborates this method. There is also a practical argument that speaks for studying male adults rather than larvae: the former can be obtained easily by hand-collecting and traps (especially Malaise traps), while the latter are more difficult to find. This argument is especially relevant for research into the biodiversity of Micromyinae, both in the temperate (JASCHHOF \& JASCHHOF 2009) and tropical (JASCHHOF \& JASCHHOF 2014) zones, of which the vast majority is obviously not yet collected, described and named. Simply put, without the use of Malaise traps and sweepnets we would know only a very small fraction of the Micromyinae that we know today. Even so, we still know little about females, larvae, and molecular diagnostics of these species, one reason being that too few people are concerned with Micromyinae. 
Having worked on Micromyinae taxonomy for more than 20 years, the present author has seen his skills in differentiating among similar morphospecies improve with time. The new species described here are an outcome of this long-term learning process. More generally expressed, it appears that the skills of a morphotaxonomist undergo further refinement as circumstances permit. This observation is not as trivial as it may seem. One aspect of it is that a taxonomic author has to be prepared to correct one's own earlier results-an issue that includes a mental dimension. Another aspect concerns methodology and, in further consequence, logistics. It is useful, apparently, to collect and preserve a great number of specimens of a species (from different localities, from different times of the year, preserved in different ways), so as to have material available when the need for re-examination appears. In terms of economy this means that it is certainly more cost-effective to maintain (i.e. preserve, develop, and keep readily accessible to students) large museum collections as archives of biological specimens rather than to search anew each time specimens of a particular taxon are needed for study. Finally, it occurs to me that in a societal environment that does not facilitate advancement of the skills necessary to master taxonomically demanding groups, science loses the wherewithal for identifying difficult species, even in the molecular era. What I regard here as the evolution of a morphotaxonomist's skills might be considered by others as a degree of subjectivity that is undesirable. The fact that there is a subjective component in taxonomic decisions supports the misconception that the employment of automated systems could eliminate this disturbing factor. A recent study of Aprionus KIEFFER, another genus of Micromyinae, has shown the relevance of morphological scrutiny in assessing the results of DNA barcoding (JASCHHOF, submit.). Automated systems are certainly capable of performing DNA sequencing and analysis, but only the expert-taxonomist can assess what the results of such analyses mean for the delimitation of species.

There is another aspect regarding DNA barcoding, which is sometimes seen as an alternative to morphotaxonomic study. For the Campylomyza serrata group, as for many other Micromyinae, it is costly to obtain fresh specimens useful for molecular work. (Note that all the specimens known as belonging to serrata-like species are permanently mounted in Canada balsam.). The problem here is twofold. First, some of the species concerned are evidently rarely encountered in the field, a fact that minimizes the chances to collect additional specimens. Second, male Micromyinae specimens in ethanol can be assigned to Campylomyza using a stereoscopic microscope, but to establish that they belong to the serrata group requires compound microscope study of the genitalia. In practice this means clipping off and slide-mounting the genitalia of each single Campylomyza male (for microscope study), and keeping the body separately in ethanol (for possible
DNA extraction). Integration of these tasks into the routine of Campylomyza (and other Micromyinae) identification would be time-consuming, especially when a project requires the processing of large numbers of specimens, meaning that this extra effort has to be scheduled and budgeted.

\section{Acknowledgements}

Research resulting in this publication was performed as part of the project Gall Midges (Diptera: Cecidomyiidae) of Sweden, which is funded by Svenska ArtDatabanken (Swedish Species Information Centre) within the framework of Svenska Artprojektet (Swedish Taxonomy Initiative) (dha 2014-150 4.3). The Gall Midge Project is supported by Station Linné, Öland's Skogsby, Sweden. A number of the specimens studied here were provided over the years by fellow dipterists, whose names are listed in the Specimens studied sections. The manuscript was carefully read and commented on by Raymond J. GAGNÉ and KeITH M. HARRIS.

\section{References}

JAschноғ, M. 1998a: Neue Gallmücken-Arten aus der Paläarktis (Diptera, Cecidomyiidae, Lestremiinae). 3. Beitrag: Gattungen Campylomyza, Bryomyia, Heterogenella, Xylopriona und Polyardis. - Studia dipterologica 4 (1997): 259-274.

JAsCHHOF, M. 1998b: Revision der „Lestremiinae“ (Diptera, Cecidomyiidae) der Holarktis. - Studia dipterologica Supplement 4: 1-552.

Jaschно, M. 2009: Eine aktualisierte Artenliste der Holzmücken Deutschlands, unter besonderer Berücksichtigung der Fauna Bayerns (Insecta: Diptera: Cecidomyiidae: Lestremiinae). - Spixiana 32 (1): 139-151.

JaschHof, M., submit.: A review of the Aprionus flavidus group, with description of two new species close to Aprionus betulae (Diptera: Cecidomyiidae, Micromyinae). - Studia dipterologica.

JaschHof, M. \& JaschHof, C. 2009: The Wood Midges (Diptera: Cecidomyiidae: Lestremiinae) of Fennoscandia and Denmark. - Studia dipterologica Supplement 18: 1-333.

JAschноF, M. \& JAschно, C. 2014: Zadbimyia, a new genus of asynaptine Porricondylinae (Diptera: Cecidomyiidae) with twenty-two new species from the cloud forest of Costa Rica. - Zootaxa 3866: 1-29.

Jaschhof, M.; Skuhravá, M. \& Penttinen, J. 2014: Checklist of the Cecidomyiidae (Diptera) of Finland. In: KahanpäÄ, J. \& SAlmela, J. (eds): Checklist of the Diptera of Finland. - ZooKeys 441: 103-118. 